\title{
FORMATION OF HIGH SCHOOL STUDENTS' SAFE BEHAVIOUR WHILE TERRORIST ATTACKS
}

\author{
Tetiana Veretenko \\ Borys Grinchenko Kyiv University, Ukraine \\ Anton Trebe \\ Borys Grinchenko Kyiv University, Ukraine \\ Olena Bieloliptseva \\ Kharkov humanitarian-pedagogical academy, Ukraine
}

\begin{abstract}
The attention is drawn to the possibility of terrorist attacks in Ukraine. The essence of safe behaviour during a terrorist attack is revealed in the article. The purpose of the article is to determine the rules of behaviour for high school students in the case of a terrorist attack, the action algorithm of high school students on receiving information about a terrorist threat; rules of safe behaviour in social networks, which are actively used by terrorists, who attack high school students to participate in their groups and terrorist acts; to present a formation program of high school students'safe behaviour while terrorist attacks and show its effectiveness. The results of the experimental implementation of the program for formation of high school students'safe behaviour during terrorist attacks and emergencies are analyzed after asurvey carried out. According to the results summarised a conclusion is made to activate social and pedagogical work in the field of forming students'safe behaviour while terrorist attacks and emergencies.
\end{abstract}

Keywords: safety, behaviour, high school/senior students, terrorist attack, program for formation of high school students'safe behaviour.

\section{Introduction}

Terrorism, as a negative social phenomenon, brings a great problemin the lives of people from all countries of the world. The phenomenon of terrorism is a real threat to national and international security. Violent terrorist attacks are the reasons of great anxiety in the world because they are getting new forms and methods with modern techniques and technological means. The later fact in its turn leads to the growth of victims among civilians every year.

In most cases senior students do not know the rules of behaviorin the case of a terrorist act, the algorithm of actions when receiving information about a terrorist threat.They do not follow the rules of safe behaviour surfing social networks but follow the instructions of terrorists in some cases. This fact indicates then ecessity of preventive work activation. The development and implementation 
of the training program not only inform high school students about the rules of behaviour while terrorist attacks, while surfing in social networks, but also provide them with an algorithm of actions in cases of terrorist attacks, help to implement the safe behavior of high school students.

\section{Formation of Research Problem}

Now a days presence on the Ukrainian territory of different groups ready to commit terroristic actions is an actual problem. Particularly, the greatest risk is connected with the temporarily occupied territories of Luhansk and Donetsk region. Difficult social and political events in Ukraine affect the life of young people; the possibility of terrorist attacks is becoming a serious threat, which requires great attention and support from the state and social and pedagogical specialists to form safe behaviour of youth. The fact that there are supporters of terrorist organizations on the territory of Ukraine gives reasons for professional intervention, detailed pedagogical and preventive measures to make a contribution into the formation of high school students' safe behaviour and also into the formation of the actions algorithm during terrorist attacks.

The development of stablemoraland strong-willed characteristics of high school students creates conditions for formation of safe behaviour and feelings of security and safety, for adoption of the actions algorithmin the situations which are potentially dangerous for a person or the ones around he or she.

The purpose of the article is to analyze the safe behaviour of high school students during a terrorist attack as well as the results of implementation of a training program as for the formation of high school students'safe behaviour during terrorist attacks.

\section{Analysis of Recent Research and Publication}

Safe behaviour formation is a process which mechanisms are ambiguously considered by various domestic and foreign experts (N. Avdeeva, A. Berezovsky, L. Hurash, N. Lati, O. Knyazeva, Y. Kit, N. Liz, I. Pistun, G. Selie, R. Storksha, S. Freud, T. Khromtsova). Causes and conditions analysis of the terrorism origins, general characteristics of some of them, administrative, law-and-international aspects of this issue became the subject of the researches by such scientists as Y. Avdeev, V. Vityuk, O. Dmitriev, S. Efirov, K. Zharinov, V. Zhuravel, V. Zagladin, O. Zdravomyslov, I. Iliinsky, E. Kalnitsky, V. Kantsir, S. KaraMurza, V. Lipkan, Y. Lyakhov, L. Modzhoryan, G. Ovchynnykov, Y. Pain, O. Panarin, B. Putilin, K. Salimov.

The analysis of the researches by P. Anokhin, A. Weis, E. Ilyin, V. Lefterov, I. Pavlov, O. Timchenko, D. Uznadze, D. Watson allows to consider the formation 
of safe behaviour as a complex dynamic process; M. Snitko defines social and pedagogical conditions for the formation of adolescents' safe behaviour while surfing the Internet, R. Vasylieva emphasizes the need to prepare future teachers to conduct formation of teenagers'safe behaviour during extracurricular activity.

\section{Literature Review}

The world is surviving a crisis of economic, environmental, financial, political nature, but the greatest danger (because of its massiveness and unpredictability) is the crisis associated with terrorist acts which have resonated all over the world and have been an actual threat since the late 90s of the twentieth century.

The Global Terrorism Index and the rating of the countries where the acts of terrorism have been committed indicate the poor position of Ukraine among European countries. Recently Ukraine has occupied position 20 among the countries with a high risk of terrorist attacks, which is the worst indicator among European countries (Table 1).

Table 1 Ukraine's Position in the Rating of The Global Terrorism Index

\begin{tabular}{|l|c|c|c|c|c|c|c|c|}
\hline $\begin{array}{l}\text { Ukraine's position in } \\
\text { the rating }\end{array}$ & 56 & 51 & 11 & 12 & 17 & 6 & 5 & 4,7 \\
\hline Year & 2012 & 2014 & 2015 & 2016 & 2017 & 2018 & 2019 & 2020 \\
\hline
\end{tabular}

In November 2020, the Global Terrorism Index released research data from 163 countries. Iran, Afghanistan, Nigeria, Syria and Pakistan took the first five places of the Global Terrorism Index. Ukraine was number 4,7. Thus, the risk of terrorist attacks actualises the problem of youth' safe behaviour.

S. Gvozdiy thinks that safe behaviouris a kind of activity that does not contain danger, protects a person from danger, does not cause harm to personality and nature (Gvozdiy, 2007). I. Shchegolev defines safe behaviour as a unity of 3 components, the reality of which significantly influences getting a comfortable level of interaction between a personand the environment. They are prediction of danger, avoidance of danger, overcoming danger (Shchegolev, 1998). We think it's important to mention the opinion by D. Kolesov, who believes that behaviourin modern society must meet two criteria: efficiency and ethics. According to him, effectiveness is essential because it is crucial to the survival during terrorist attacks. Ethics inbehaviour is manifested in following requirements of morality. Such behaviour does not harm other persons, does not make troubles for meeting needs of others. Considering the questions of behaviour efficiency, the author distinguishes two types of it: initiative and 
standardbehaviour. He characterizes the following features of the initiative behaviour: diversity, speed, flexibility, action mode switching; taking into account the situation and its dynamics; the person's ability to adapt one's actions to the situation; the ability to act on the basis of forecasting, which means to be ahead of, the ability to act with full power, not to be stopped by difficulties; the ability to carry through; a realised behaviour orientation to the aim (Kolesov, 2004). The purpose of the research J. Bond (2009) was to show how university teachers could help students acquire their skills in techno ethics, ecological ethics, computer ethics skills (Bond (2009). M. Snitko and T. Veretenko (2011) define "safe behaviour" as a way for self-realization and a complex of actions implemented by children and young people, which are characterized by knowledge about the risks and rules of behaviour, by skills of optimal responding being in the challenging situations, of emotions controlling and being responsible as for one's own acts (Snitko\& Veretenko, 2011).Unfortunately, E.OgrodskaMazur and P.Saukh show in their work that every tenth young person in Ukraine is not influenced by moral norms(Ogrodska-Mazur, Saukh, 2019).

\section{Methodology}

The investigation was being carried out in Kiev and Kharkov schools during 2019-2020 academic year. It was suggested to define the following:

1) senior students' knowledge about terrorist attacks and safe behaviour during terrorist attacks (by questionnaire for senior students); the results of the questionnaire (167 students of Kiev and Kharkov schools, Ukraine) allowed us to admit that the students had learnt the algorithm of actions while terrorist attacks. We also can state that the idea about terrorism as a negative thing was formed.

2) the behavior of high school students algorithm formation (by the participation in the training program developed). The implementation of the training program developed helped to provide high school with information about a terrorist act as a negative phenomenon, about conflict situations and the ways out of them; to activate students' interest as for safe behaviour and positive response to the algorithm ofactions while terrorist attacks.

One of the methods of our study was the analysis of statistical data as for terrorist attacks in the world and in Ukraine. In the study, we used methods of surveys, questionnaires and individual interviews. The questionnaire consisted of three blocks of questions. The first contains questions about information as for terrorist attacks; the second one defines behaviour while terrorist threats; the third block deals with knowledge of the actions algorithm while conflict situations and terrorist attacks. In addition to the questionnaire, we conducted individual 
interviews lasting up to 20 minutes. The respondents answered the same questions in a more expanded form. Additional questions were personalized considering the answers got during the interview.

To obtain more reliable data we organized our study confidentially. Each participant agreed to participate in the survey and interview.

During the interviews we followed ethical rules. If someone didn't want to answer some questions, we didn't insist. One of the main conditions of the study is one's voluntary participation.

\section{Research Results}

The school period, and especially the senior high school one, is the most favourable for developing a person's feeling of personal and collective safety. Obviously, it is easier at this age to form motives which encourage high school students to follow the rules and regulations of safe behaviour at home, on the street, at school, in the country. The main leitmotif of high school students' mental development is the formation of a new, still unstable self-consciousness, a change in the self-conception, an attempt to understand oneself and one's capabilities. A feeling of belonging to a special community appears, and the value of it is the basis for students' personal moral judgments, is of great importance. At the same time a high school student is excited by new thoughts, feelings, anxieties, the young person seeks different forms of communication, friendly relations and is influenced or consciously involved into the process of socialization. The ability to behave independently is formed at this age. It leads to destruction of previous interests and motives and formation of a new motivational sphere, as well as to the search for new forms of behaviour.

As the school age is favourable for the formation of a personal safety feeling, we conducted a test experiment. The developed questionnaire "Surveys for Saving of Life" made it possible to identify senior high school students' realisation of the actions algorithm during terrorist attacks and formation of ideas about the terrorism as a negative phenomenon.

Survey conducted for senior high school students showed that they understand terrorism as: influence on the psychological state of society; violence because of apolitical or religious aim; use of violence; political activity oriented to take control; use of weapons to achieve a specific purpose; an act of aggression; damage to the environment; negative actions which are dangerous for human lives; annihilation of a nation; crime; destruction of property; a threat to humankind. To sum up, we can conclude that senior high school students do not fully realise the concept of terrorism and terrorist attack.

An important thought is the one about what drives people to take the path of a terrorist. It is the desire to achieve one's goal, gain power or material gains, 
religious beliefs, thirst for revenge. It is interesting that, senior high school students have an opinion, that computer games can also be a factor in encouraging aggressive actions, a large number of games is violent, and young people are one of the greatest users of online shooters and strategies. High school students also think that one of the factors leading to the lifestyle of a terrorist is psychological problems, such as problems in the family, bulling by peers, death of the ones loved, difficulties in self-realization, life problems, lack of moral and ethical principles, unformed behaviour, not-understanding of terrorism as a negative phenomenon.

One of the main factors in the safe behaviour formation is realising one's own personal safety and his or her social environment, a feeling of safety. Only $30 \%$ of high school respondents consider themselves protected from terrorists, $34.7 \%$ consider themselves unprotected and feel danger from terrorists and terrorist groups in the territory of Ukraine, $16.3 \%$ of respondents feel protected only next to law enforcement officers. High school students determined how protected from acts of terrorism they feel according to a ten-point scale, it is 6 points. So, we can conclude that high school students demonstrate quite a lot of anxiety and find themselves not protected.

As for the question "Why do so many young people support terrorism?", $27 \%$ of the senior high school students answered the following way: young people feel the acute injustice of the world order; are easily managed by different groups and religious sects because of their unstable beliefs, insufficient level of information; are radical in their views; spread of extremism phenomenon; influence of advertising and cinema; introduction through social networks; plenty of free time; low informational level as for the negative phenomenon of "terrorism"; uncompleted formation of young people values. Such answers provide a broad field for conducting social and pedagogical work as for formation of high school students' safe behaviour during terrorist attacks

In order to let the state inform about emergencies and terrorist or military actions, it is necessary to involve the media and the "alert system" (sound signal, information about emergency services further actions). But we must admit that $72 \%$ of high school seniors students know nothing about the existence of such a system; $12 \%$ consider it to be alarm systems and alerts delivered through the mass media; $10 \%$ know that this system exists, but consider it imperfect as for the capability to inform everyone about the emergency, 6\% of young people interviewed believe that this is informing by television. So, the survey indicates that most senior high school students don't realise at all how to prevent an urgent situation, what to do, and whether the system is perfect.

It is important to collect necessary emergency supplies for emergencies or terrorist attacks, but the greater part of high school students does not know what must be among such things. Unfortunately, this fact immediately reduces their 
ability to maintain their own health. Some respondents are ready to take a first aid kit and documents, others hope for emergency shelters and one's rather quick return to a routine life style.

Respondents insist that terrorists actively use social networks to involve individuals into their groups and encourage radical views and decisive actions. They also observed advertisements with bright slogans and can give examples of suicidal groups, such as "Blue Whale", "Wake Me Up at 4:20", "Sea of Whales", "f57", "Silent House", and others. The answers indicate the necessity to carry out social and educational work on safe surfing social networks and the Internet. High school students believe that their safety depends on them and in difficult situations they can only rely on their knowledge and skills.

Among the respondents, 39.8\% feel threat from terrorist groups, and 5.6\% believe that they can meet terrorists in the territory of Ukraine. A lot of students feel anxiety, especially concerning the regions of Donetsk and Luhansk which are constantly in the zone of combat actions.

It is obvious, that understanding of what to do during emergencies and following a certain algorithm of actionsis the formed safe behaviour, creating conditions of protection and security for the person and the others next to. Unfortunately, 95\% of respondents do not know what to do and what are the rules of actions during terrorist attacks and while dealing with terrorists. The formation of safe behaviour, theoretical and practical measures directed by educational institutions, public organizations and emergency services should be involved into constructing the actions algorithm for high school students during terrorist acts.

One of the main factors for safe behaviour during terrorist acts is knowledge as for the evacuation procedures and the evacuation plan in buildings, shopping malls, educational institutions, public places, stations, etc. High school students are familiar with the evacuation plan in the subway - 29.2\%, not familiar with $37.5 \%$; students have looked through once, but the exact evacuation scheme can't be remembered $-29.2 \%$, believe that the evacuation plans can't be found $-4.2 \%$.

As for the evacuation plan at shopping malls, it was reviewed by $45.8 \%$, not seen by $31.2 \%$; was looked through once, but not remembered by $16.7 \%$; attention is paid to from time to time by $6.3 \%$.

As for the evacuation plan at school, $75 \%$ have looked through; $12.5 \%$ are not introduced to; $12.5 \%$ we introduced to once but can't remember details.

The data obtained indicate that students are given the information about the evacuation plan at school, but there is a certain percentage of high school students who know nothing about the evacuation exits which are very important as the first action in the case of a terrorist attack or emergency. So, the results of the survey show insufficient informing activity as for introduction with evacuation plans in shopping malls, public transport, educational establishments. 
The respondents also state that information about emergencies and evacuation plans given at high school is not worked out (82\%); such activity is not carried out at school (6\%); the activity is carried out not correctly (2\%). The actional gorithmis focused on keeping calm, following recommendations of teachers to be careful, but such kind of behaviour can't be rational during certain emergencies or terrorist acts, such as capturing a building by terrorists.

So, we face the necessity for high school students to develop safe behaviour during terrorist attacks, as well as to be informed about the algorithm of actions. It is also crucial to carry out social and pedagogical work to realize the knowledge obtained and the importance of safe behaviour.

\section{Discussions}

Developing and conducting a training program designed to informand develop saf behaviour of high school students during terrorist attacks is one of the main preventive measures.

The research showed that informative activity should becarried out constantly, the safe behavior of high school students depends on constant search for information and its assimilation. The training program in volves not only study ingstandards and rules of behavior while terrorist attacks, but also: forming under standing the value of safety and safe behaviour; creation of conditions for personal potential of senior high school students; raising the student's terrorist attacks risks informing level; motivating a high school student to develop and follow the actions algorithm of safe behaviour during terrorist attacks.

One of the main aspects of the training program is the behaviour alcomponent of high school students'safe behaviour during terrorist attacks formation, related to the formation of relev ant theoretical and practical knowledge. The maicontent of this component is the development of high school students'life essential skills. Namely, to increaseresistance to various social influences, to make adequate decisions according to the situation happening while terrorist attacks; to be abletoresist pressure from terrorists, to control one's own action and estimate the situation adequately.

\section{The Training Program}

The training program includes 6 lessons:

"Acquaintance" - giving participants the opportunity to get to know each other, creating a friendly atmosphere, improving attent ivelistening skills, relaxing, self-presentation;

"Communication skills as one of the safe behaviour factors" communication skills development as one of the preventive elements for conflict 
situations. For mingan understanding of how to formulate one'sown interests in such away as to beheard by another person and to be able to expres sone'sopinion freely;

"Terrorism is a danger to humanity" - to introduce students to the peculiarities of terrorist acts and the phenomen on of terrorism in the world;

"Let's say terrorism "no" - to learn the algorithm of actions of feredby students and to inform about the correct sequence of actions in the situation of terrorist attacks;

"Conflict" - understanding the concept and nature of "conflict"; communication in a conflict situation; advantages and disadvantages of a conflict;

"I know" - to learn theoretically and practically the knowledge of safe behavior during terrorist attacks, following the algorithm of actions for saving one'sown life and the lives of the others next to.

Our experimental study carried out allowedus to formulate the following recommendations:

1. The main task of a social educatoris to keep constantly informing about safe behaviour, to provide theoretical and practical knowledge.

2. To promote the comprehensive development of high school students as for safe behavior.

3. Implementation of the developed training program allowed:

- $\quad$ to provide high school students with information about a terrorist actas a negative phenomenon;

- to rein force the importance of communication;

- $\quad$ to realize what a conflict situation is and the way to deal with it;

- $\quad$ to increase senior high school students' interestin safe behaviour;

- to percept the algorithm of actions during terrorist attacks positively.

The main objective of the training program was to promote the interes to fhigh school students, to create a motivation for high school students to develop safe behaviour.

\section{Conclusions}

Difficultsocial and political events in Ukraine affect the life of high school students; the possibility of terrorist attacks is becoming a serious threat, which requires great attention and support from social and pedagogical specialists to form safe behaviour of youth. It is important to carry out social work with high school students to provide the information and practical knowledge in the case of a terrorist threat, to promote peaceful solution of conflict situations. Implementation of the training program developed allowed to provide high school 
students with information about a terrorist actas a negative phenomenon; to rein force the importance of communication; to realize what a conflict situation is and the way to deal with it; to percept the algorithm of actions while terrorist attacks positively. The study carried out is aimed to learn to lerance, to lerance to the others, peacefulness, kindness, willingness to someone next to you.

\section{Acknowledgement}

The study is a part of the scientific research implemented by the Institute of Human Sciences of the Borys Grinchenko Kyiv University "Personality in Conditions of Social Transformations of Modern Ukraine", registration number: 0116U002960, duration - 5.2016-5.2021.

\section{References}

Bond, J. (2009). Professional Ethics and Corporate Social Responsibility. Process Safety and Environmental Protection. Process Safet Environmental Protection, 87, 184190. https://doi.org/10.1016/j.psep.

Gvozdiy, S. P. (2007). Preparation of future natural cycle teachers for teaching students the basics of safe behavior. phD in Pedagogical Sciences: 13.00.04. Odessa. 2007.

Kolesov, D. (2004). Initsiativnoye i shablonnoye povedeniye. Razvitie lichnosti, (1), 62-70.

Ogrodzka-Mazur, E., \& Saukh, P. (2018). The Social and Cultural Tendencies in the Environment of Contemporary Youth. A Polish-Ukrainian Comparative Study of the Structure of Axiological reality. The New Educational Review, 57(33), 72. https://doi.org/10.15804/tner.2018.57.3.05

Shchegolev, I. (1998). Razvitiye pedagogicheskoy gotovnosti uchitelya bezopasnosti zhiznedeyatel'nosti (Na osnove ispol'zovaniya situativ.-imitats. Modeli rovaniyaucheb. informatsii) [Development of pedagogical readiness of the safety of life activity teacher (On the basisof of situation-imitative modeling of educational information use)] phD in Pedagogical Sciences: 13.00.08. University St.Petersburg, 1998, 178 p.

Snitko, M \&. Veretenko, T. (2011). Determinantu formuvannya bezpechnoi diualnosti molodi v Internet meregi. Wspolczesne determinanty bezpieczenstwa., 215-220. 